\title{
Os processos de subordinação e de coordenação
}

\section{Fernando Moreno da Silva}

Pós-doutorando em Linguística e Língua

Portuguesa (UNESP/FCLAr - Bolsista da FAPESP).

Resumo: 0 artigo propõe rever as principais dificuldades em torno dos processos de subordinação e de coordenação, retomando sobretudo as reflexões de Carone (2001). Uma das propostas para tratar desses processos é trabalhar com o conceito de translação, termo dado por Tesnière (1965), como traço de distinção entre subordinação e coordenação, pois na subordinação ocorre a translação, ao passo que na coordenação, não. Além disso, procura-se ressaltar a importância da abordagem tanto sintática quanto semântica para tratar desses processos.

Palavras-chave: Sintaxe; subordinação; coordenação
Résumé: L'article propose d'examiner les principales difficultés dans le processus de subordination et de coordination, en particulier les réflexions de retour Carone (2001). Une proposition visant à faire face à ces processus est de travailler avec le concept de traduction, un terme donné par Tesnière (1965), comme un signe de distinction entre la subordination et de coordination, comme cela arrive à lier la traduction, alors que dans la coordination, non. En outre, nous cherchons à mettre l'accent sur l'importance de s'attaquer à la fois syntaxique et sémantique des processus pour y remédier.

Mots-clés: Syntaxe; subordination; coordination 



\section{Definição}

O estudo da língua se compõe basicamente de três partes: fonética/fonologia (estudo dos sons), morfologia (estudo dos vocábulos) e sintaxe (relação entre os termos na oração). Um dos tópicos fundamentais da sintaxe (do grego syntasis: ordem, disposição) é o estudo da subordinação e da coordenação, conhecidos tradicionalmente como dois tipos de ligação entre orações.

Costuma-se associar a coordenação a unidades independentes, e a subordinação a unidades dependentes, definindo os dois processos por critérios semânticos e sintáticos. Assim, a subordinação é definida em termos de dependência sintática (oração subordinada funciona como um termo que exerce função na principal) e semântica (subordinada não tem sentido completo sem a principal). Já as orações coordenadas são definidas como independentes por possuírem sentido completo em relação à principal.

Nas gramáticas de natureza normativa, há autores que defendem ora o critério sintático, ora o critério semântico, ou os dois ao mesmo tempo.

Bechara (1988) adota os dois critérios, definindo oração independente como aquela que possui sentido completo (critério semântico) e que não exerce função sintática em relação à outra.

Kury (1987) refere-se ao critério semântico, definindo as orações coordenadas como as que têm sentido por si mesmas, e a orações subordinadas como dependentes de uma principal.

Rocha Lima (1998) se utiliza de um critério sintático. Define a coordenação como uma sucessão de orações independentes do ponto de vista gramatical. E caracteriza a subordinação como sendo uma oração principal que traz como dependente uma ou mais orações presas à principal.

Ignácio (2003) igualmente se baseia no critério sintático. "Uma oração se diz coordenada em relação a outra, quando guarda, em relação uma independência 
sintática, ou seja, não exerce função sintática em relação a essa outra" (p. 74). Já a "oração subordinada nada mais é que a expansão, em forma de oração, de um dos termos constituintes (sujeito, objeto, etc.)". (p. 77).

A adoção de critérios distintos para tratar de um mesmo assunto problematiza a questão, trazendo dificuldades à compreensão desses processos.

\section{Subordinação e coordenação nos níveis linguísticos}

Em geral, lembram-se dos processos de subordinação e de coordenação apenas quando se trata do estudo do período (frase composta de uma ou mais orações). Mas esses dois processos são fenômenos que não ocorrem apenas entre orações. Essas relações sintáticas aparecem também entre os termos da oração.

(1) Cortou (regente) a bola (regido)

Entre os termos "cortou" e "bola" há uma subordinação, quando "bola" completa o verbo "cortou". Tem-se, pois, uma relação de dependência entre os termos, sendo "cortou" subordinante, e "bola" subordinado.

(2) Cortou (regente) a bola e a grama (regidos)

Em (2), os termos "bola" e "grama" estão numa relação de coordenação entre si; ambos possuem a mesma função sintática (objeto direto), independentes do ponto de vista sintático.

Além do nível sintático, os processos de subordinação e de coordenação estão presentes nos outros níveis da estrutura da língua.

(b) /(r)olo: bolo ou rolo (nível fonológico)

cort(e)/cort(ou): nível morfológico

corte (de cana)/(da saia): nível sintático 


\section{Subordinação}

Nas gramáticas, quando se trata de estudar o período composto, primeiramente se foca a coordenação; depois, a subordinação. Carone (2001) lembra que a antecipação da coordenação torna a compreensão mais difícil. Para entender os critérios da independência das orações coordenadas, não somente em termos semânticos, a autora diz que se abordasse primeiro a subordinação, o estudo da sintaxe se tornaria mais claro. Afinal, a subordinação é a mais coerente, pois é a ordem natural na frase: as palavras se organizam em sintagmas, e estes, em oração. Só depois disso se instala a coordenação.

A subordinação estabelece hierarquia entre os termos e as orações.

a) entre termos:

(3) Ele disse a verdade (a expressão "a verdade" completa o verbo "dizer")

b) entre orações:

(4) Ele disse que nunca voltaria (a oração "que nunca voltaria" completa o verbo)

Quando se trata de período, como no último exemplo (4), conclui-se que a "oração subordinada nada mais é que a expansão, em forma de oração, de um dos termos constituintes (sujeito, objeto, etc.)". (IGNÁCIO, 2003, p. 77).

Em (3), "verdade" funciona como objeto direto. Em (4), a oração "que nunca voltaria" é uma expansão da oração principal, permanecendo toda a oração com a função sintática de objeto direto.

As orações subordinadas são de três tipos: substantiva (funciona como um substantivo), adjetiva 
(como adjetivo) e adverbial (advérbio). As adjetivas e as adverbiais funcionam como complemento do termo da oração principal:

(5) Conheceu uma criança (que cantava alegria)

(6) Eu iria à festa (se não fosse o compromisso)

Já as orações substantivas são necessárias à oração subordinante para completar o sentido do período:

(7) Foi preciso que o professor falasse alto

A subordinação, portanto, se caracteriza por dois fatores: (i) estabelece hierarquia entre a oração principal (subordinante) e a oração expandida, que recebe o nome de subordinada; (ii) cria função, pois a oração subordinada desempenha sempre uma função sintática (sujeito, complemento verbal, adjunto adnominal, adjunto adverbial, etc.) em relação à outra oração (substantiva) ou a um termo da outra oração (adjetiva e adverbial).

Assim, as orações subordinadas serão classificadas de acordo com a função sintática do termo correspondente. Por exemplo: se toda a oração funcionar como objeto direto, será chamada "objetiva direta".

\section{Coordenação}

Carone (2001) estabelece algumas características prévias da coordenação:

a) os elementos coordenados têm a mesma função sintática;

Essa afirmação precisa ser melhor explicitada. Ora, a identidade funcional dos termos coordenados pressupõe também a subordinação. Se há, por exemplo, 
dois objetos, estes se encontram subordinados a um verbo, afinal, a função desses objetos só se define em relação ao verbo. Trocando em miúdos, não existe coordenação sem subordinação.

b) os elementos coordenados pertencem a um mesmo paradigma;

Para contrariar essa propriedade, a autora ( $p$. 25) faz a ressalva de que "coordenação" e "associação paradigmática" não se pressupõem mutuamente. E exemplifica com artigos e pronomes adjetivos, que podem ser comutados, mas não coordenados:

(8) o homem saiu / aquele homem saiu / ${ }^{*}$ o aquele homem saiu.

Mesmo quando se combinam, os termos não configuram uma coordenação:

(9) o homem saiu / outro homem saiu / o outro homem saiu.

c) a coordenação forma sequências abertas, não sintagmas;

Nas coordenadas, a formação de uma sequência aberta só se aplicaria, como ressalta Carone (2001), às alternativas e às aditivas. Em relação aos demais tipos de coordenação, o que ocorre são construções binárias, introduzidas por conjunções com valor retrojetivo: oposição ao que foi expresso anteriormente:

(10) Deus é bom, mas justo e severo. 
Nesse exemplo, "justo" e "severo", ligados por adição, formam um todo que se opõe a "bom". Dessa forma, as frases coordenadas também se organizam em pares, que podem constituir uma nova unidade; a identificação de tais pares deve ser guiada não apenas pelo tipo de conjunção, mas também pelo sentido da frase.

d) coordenam-se tanto orações como termos de uma oração.

Segundo a abordagem estruturalista, uma frase como "João e Maria saíram" seria o resultado da soma de duas orações: "João saiu + Maria saiu". Com a junção, haveria supressão dos elementos repetidos, sendo a concordância um mero reforço. Com essa hipótese, a de orações originais pressupostas na oração, haveria um só tipo de coordenação. Mas há casos que derrubam essa hipótese:

(11) Ela sentou-se entre João e Maria.

Com esses termos ligados pela preposição "entre", não se pode dizer que houve coordenação de termos de orações originais das quais foram excluídas as repetições.

\section{Coordenadas explicativas versus subordinadas adverbiais causais}

As discussões tratadas até aqui esclarecem em linhas gerais algumas diferenças e semelhanças entre os períodos compostos por coordenação e por subordinação. Mas para problematizar a discussão, discorre-se abaixo sobre um ponto que gera muitas dúvidas na determinação de um ou de outro período. Trata-se da oposição entre orações coordenada explicativas e orações subordinadas adverbiais causais. 
Cláudio Cezar Henrique (2005, p.101) estabelece a diferença entre essas duas orações no campo semântico. Partindo desse pressuposto, explica que a oração explicativa $B$ é sempre consequência da oração $A$, que normalmente é encerrada com pausa:

(12) O carro tem algum problema, pois está soltando fumaça. (Coordenada explicativa)

(13) O carro está soltando fumaça, pois tem algum problema. (Subordinada causal)

Nesses exemplos específicos, aplica-se a técnica do espelho apontada por Carone (2001), pois a inversão da oração coordenada sindética explicativa resulta na oração subordinada adverbial causal (que remete a um fato anterior à oração principal).

O mesmo raciocínio da causa e da consequência apresenta Cegalla (1998, p. 342), quando diz que a subordinada exprime a causa de um fato, e a explicativa o motivo da declaração anterior:

(14) João está triste porque perdeu o emprego. (adverbial causal, pois a perda do emprego é a causa de sua doença).

(15) A criança devia estar doente, porque chorava muito. (explicativa, pois o choro não podia ser a causa de sua doença).

Rocha Lima (1998) ratifica a ideia:

A oração subordinada de que e porque é parte de outra oração (...). E entre elas existe, necessariamente, uma relação de 'causa' e 'consequência'. Eis aí a verdadeira pedra de toque: a oração principal encerra sempre a consequência do que se declarou na subordinada, e nesta, por sua vez, se apresenta a razão se a qual não haveria aquela consequência. (p. 275) 
(16) Espere-me um instante, que não demorarei. (coordenada explicativa, pois não há nenhuma relação de causa e consequência).

(17) O capitalista se matou porque estava arruinado (subordinada causal, pois "estar arruinado" foi o que acarretou o "ter-se matado")

Embora a explicação com base no raciocínio da causa e da consequência pareça suficiente para resolver o problema da distinção entre as duas orações, Celso Cunha e Lindney Cintra (2007, p. 598) apresentam o seguinte exemplo de oração coordenada sindética explicativa:

(18) Um pouquinho só lhe bastava no momento, pois estava com fome.

Entende-se ser a fome um fato anterior ao que poderia ser chamado, em uma análise apressada, de oração principal, mas, partindo do pressuposto de que não ocorre o processo de translação, que caracteriza, segundo Carone (2001), o período composto por subordinação, tal oração deve ser considerada coordenada sindética explicativa.

Como se vê, a distinção entre coordenada explicativa e subordinada adverbial causal é uma polêmica na sintaxe.

\section{Translação: traço de distinção entre subordinação e coordenação}

No início deste artigo, a discussão começou definindo os processos de subordinação e de coordenação. Foi dito que a dependência é uma propriedade distintiva. Orações subordinadas seriam dependentes, e orações coordenadas, independentes. Uns defendem a dependência sintática; outros, a semântica, ou seja, restrita ao sentido. Mas é preciso esclarecer a natureza dessa dependência. 
Carone (2001) ressalta que a independência ou a autonomia não pode ser considerada a marca principal da coordenação. E essa caracterização tem sido feita pela maioria das gramáticas. Há casos em que esse raciocínio não procede. A sentença "Mas você não responde!" é tão dependente quanto "Se eu fosse um mágico...". Como se resolveria nesses casos a questão da dependência?

Carone (2001) defende a tese de que a diferença entre subordinação e coordenação estaria no processo de translação do verbo.

Para entender o processo de translação na sintaxe, é conveniente recorrer ao nível imediatamente inferior, ou seja, o morfológico. Dentro do processo de formação de palavras (MONTEIRO, 2002), mais especificamente na derivação imprópria, há a mudança de classe gramatical do vocábulo.

(19) O relâmpago assustou os moradores (relâmpago é substantivo)

(20) O comício relâmpago conquistou os espectadores (relâmpago passou a ser adjetivo)

Além de "derivação imprópria", esse processo recebe outros nomes: hipóstase (Charles Bally), conversão (Evanildo Bechara) e translação (Tesnière).

Entendido o processo da translação, termo dado por Tesnière (1965), pode-se utilizá-lo na sintaxe, na qual uma oração inteira passa a se subordinar a um termo de outra oração:

(21) O homem conseguiria a vitória se lutasse mais um pouco

A oração "se lutasse mais um pouco" fica subordinada ao verbo "conseguiria". Na subordinação, uma oração funciona como termo subordinado ou 
subalterno de outra oração. Assim o "todo", representado por uma oração, torna-se "parte" para relacionar-se com uma parte de outro "todo".

Já no exemplo abaixo, não há translação, porque as orações não se subordinam uma à outra, sendo, portanto, coordenadas:

(22) O homem conseguiu a vitória e lutou mais um pouco

$\mathrm{Na}$ coordenação, ainda que haja dependência entre as orações em determinados períodos, as orações se relacionam sem que haja a translação. São dois "todos" que se relacionam.

Disso se conclui que a diferença entre a coordenação e a subordinação reside na translação. $\mathrm{Na}$ subordinação ocorre a translação; na coordenação, não.

\section{Considerações finais}

Nessas reflexões em torno dos processos de subordinação e coordenação, o que se percebe é que não há um consenso ou uma definição única e acabada. Ora, a língua é um organismo vivo, sendo, portanto, sujeito a mudanças e a interpretações distintas. Por consequência, todos os fatos relacionados a ela igualmente estão envolvidos nessa constituição.

Ao tratar desse ponto da sintaxe, apresentaram-se visões de gramáticos e de linguistas que enveredaram por diversos caminhos na abordagem desses processos: ora pela natureza sintática, ora pela natureza semântica.

Na esteira das duas grandes correntes da linguística moderna, formalismo e funcionalismo, que ressaltam na língua, respectivamente, sua forma e sua função, pode-se concluir que, ao estudar a subordinação e a coordenação, é necessário pensar na relação de complementaridade entre o caráter sintático e o semântico. 
Um exemplo disso ocorre na proposta da abordagem sintático-semântica (IGNÁCIO, 2003) da estrutura argumental da oração.

Nessa nova proposta, que vai de encontro às propostas da gramática tradicional (estrutura bipartida em sujeito e predicado), a preocupação se concentra na estrutura argumental da oração, quando o verbo passa a ser o elemento central, estruturador da oração, formando o conjunto composto de verbo e seus elementos obrigatórios (argumentos).

Nesse princípio da centralidade do verbo (CHAFE, 1979; TESNIÈRE, 1965), os elementos obrigatórios exigidos pelo verbo recebem o nome de argumento ou constituintes oracionais, daí o nome estrutura argumental. Cada argumento possui uma função semântica, chamada de caso semântico ou papel temático. Os principais casos semânticos são:

1. Agente ou agentivo: é o instigador da ação verbal. Um ser animado que tem o constrole sobre a ação. Ex. O vizinho irritou o cachorro.

2. Paciente: recebe ação ou sofre os resultados do processo. Ex. Com o calor, o aparelho foi danificado.

3. Receptivo ou Destinatário: a quem se destina a ação verbal. Ex. Mandei a carta a Maria.

4. Beneficiário: quem se beneficia pela ação ou pelo processo. Ex. Ricardo foi premiado

5. Experimentador: quem experimenta um processo ou uma sensação. Ex. Rute demonstrou seu amor.

6. Causativo: causador de uma ação. Não tem controle sobre a ação. Ex. A chuva estragou tudo.

7. Instrumental: desencadeador de uma ação. Sendo manipulado, sempre pressupõe um agente que o manipulado. Ex. A chave finalmente conseguiu abrir a porta. 
8. Objetivo: ponto de referência de um estado. É neutro. Ex. O quadro era o enfeite da casa.

9. Origem: ponto de origem de um processo. Ex. O chuveiro fazia barulho todas as noites.

10. Locativo: lugar do evento ou de referência. Ex. Minha casa será o palco da festa.

Embora numa conclusão não se deva proceder a digressões, mencionar a estrutura argumental da oração é apenas uma forma de ressaltar a importância da abordagem sintático-semântica.

Se se insistir na exclusividade de um ou de outro, será deixado de lado o ensinamento de que a língua não é só forma, mas também conteúdo. Assim, estão corretos aqueles que decidem refletir sobre os processos de subordinação e de coordenação sob todos os vieses que possam ajudar na compreensão da sintaxe. 


\section{Referências}

BECHARA, Evanildo. Lições de português pela análise sintática. Rio de Janeiro: Padrão, 1988.

CARONE, Flávia de Barros. Subordinação e coordenação: confrontos e contrastes. 6. ed. São Paulo: Ática, 2001.

CHAFE, Wallace L. Significado e estrutura linguística. Tradução de Maria H. M. Neves et al. Rio de Janeiro: LTC, 1979

CEGALLA, Domingos Paschoal. Novíssima gramática da língua portuguesa. 41 a ed. São Paulo: Editora Nacional, 1998.

CUNHA, Celso; CINTRA, Luis F Lindney. Nova gramática do português contemporâneo. Rio de Janeiro: Lexikon, 2007.

HENRIQUE, Cláudio Cezar. Sintaxe Portuguesa para a linguagem culta contemporânea. 5. ed. Rio de Janeiro: UERJ, 2005

IGNÁCIO, Sebastião Expedito. Análise sintática em três dimensões. Franca: Editora Ribeirão Gráfica, 2003.

KURY, Adriano da Gama. Novas lições de análise sintática. São Paulo: Ática, 1987.

MONTEIRO, José Lemos. Morfologia Portuguesa. 4. ed. Campinas: Pontes, 2002.

ROCHA LIMA, Carlos Henrique da. Gramática normativa da língua portuguesa. Prefácio de Serafim da Silva Neto. 36. ed. Rio de Janeiro: José Olympio, 1998.

TESNIÈRE, Lucien. Éléments de syntaxe structurale. 2. ed. Paris: C. Klincksieck, 1965. 